\title{
Os papéis do sujeito com relação a conteúdos midiáticos no Tweetdeck: 0 produtor, o compartilhador e o leitor
}

Sandra Bordini Mazzocato

\section{Resumo}

0 presente artigo investiga os papéis do sujeito com relação ao conteúdo midiático nas redes sociais, realizando-se um estudo sobre as trocas realizadas no Twitter através do Tweetdeck. Propõe-se que o indivíduo é um disseminador de mídia, já que a dinâmica das trocas referenciais na web é interpretada pelo ponto de vista do próprio. Suas afinidades que formam seu perfil e suas interações atribuem-lhe identidade, sendo também conteúdo relevante para os contatos que forma em grupos de interesse. São abordados conceitos de cultura, mídia e representação e realiza-se uma pesquisa quantitativa quanto aos hábitos de absorção e processamento de informação no Tweetdeck. Conclui-se que o sujeito pode ter três papéis com relação ao conteúdo midiático: produtor, compartilhador e leitor.

\section{Palavras-chave:}

Papéis do Sujeito. Representação. Conteúdos Midiáticos.

Sandra Bordini Mazzocato | sandrabordini@gmail.com

Doutoranda do Programa de Pós-graduação em Comunicação Social da Pontifícia Universidade Católica do Rio Grande do Sul (PUCRS). Designer de Interface da Universidade Federal do Rio Grande do Sul (UFRGS).

\section{Introdução}

No contexto de diversidade cultural que se vive hoje, muito se discute sobre as formas como os diferentes conteúdos são disseminados. Com a expansão da sociedade em rede observa-se referências cada vez mais amplas interagindo em grupos de interesse em que o espaço físico não é mais relevante. Nos estudos voltados à cibercultura, a web é interpretada como um meio de comunicação próprio dessa realidade, por sua força potencializadora de compartilhamento de novas referências. Cada vez mais se compreende a importância de cada indivíduo para a criação e atribuição a referências presentes na mídia.

Nessa pesquisa o objetivo é investigar qual o papel do sujeito com relação ao conteúdo das mídias sociais. Ou seja, como se posiciona com relação a diferentes conteúdos midiáticos aquele que interage nesses ambientes? Especificamente para esse artigo realiza-se um estudo empírico no Tweetdeck, uma aplicação do tipo third party ${ }^{1}$ que funciona para realizar atualizações no Twitter e em outros serviços, como o Facebook, ${ }^{2}$ o Linkedin ${ }^{3}$ e 0 Foursquare. ${ }^{4}$ No presente estudo são focadas as interações realizadas no Twitter através do Tweetdeck. 
Busca-se conceitos de diversidade cultural

e novas formas de compartilhamento de

informações em rede para contextualizar 0

tema. Sabe-se que as várias tendências são

trocadas por conta da cultura participativa,

que por sua vez é ampliada com a internet. A

essa discussão são acrescentadas teorias sobre

mídia e representação do sujeito, buscando uma

explicação para a proposta de que afinidades e

interesses referentes à identidade são, em muitos

casos, conteúdos midiáticos.

Posteriormente apresenta-se 0 estudo empírico

do Tweetdeck, com dados quantitativos obtidos

através de um questionário dividido em três

partes, respondido por 167 de seus usuários.

Este aplicativo foi escolhido por tornar

possível criar uma série de personalizações na

visualização da informação e também configurar opções para tornar a postagem mais dinâmica.

Porém o objetivo é perceber os hábitos de leitura

e postagem das pessoas para identificar quais os

papéis que possuem com relação ao conteúdo.

Não se pretende realizar uma análise do

conteúdo que é compartilhado, e sim investigar

como o sujeito pode interagir com ele e como isso

afeta a rede.

\section{0 sujeito cultural como disseminador midiático}

0 sujeito vive em uma sociedade em rede

(CASTELLS, 1999) em que as informações

trocadas com contatos podem tornar-se

referências midiáticas, como de entretenimento

ou notícias. Nesse contexto a diversidade cultural

atinge caminhos mais extensos.

Cultura, para Benkler (2006), é um conjunto de

significados e símbolos compartilhados. Para ele

vivemos em uma lógica da economia da informação

em rede em que ocorre uma reconfiguração do

"quem" e do "como" da produção cultural em um

novo modelo descentralizado de produção não-

mercadológica. Ela afeta as maneiras como os

indivíduos e grupos interagem com a cultura e uns

com os outros. Nessa dinâmica a cultura torna-

se mais transparente e participativa. A cultura

participativa é inerente ao ser humano e existe

independente as redes sociais na internet. 0 foco

dessa pesquisa está em como esse processo ocorre

no contexto da cibercultura.

Para Santaella (2003) na chegada dos anos

1980 ocorre um agigantamento dos meios de

comunicação confundindo os conceitos de

cultura popular, erudito e massivo. Novas formas

Aplicações do tipo Third party (produzido por terceiros) são programas desenvolvidos para funcionar juntamente a outros programas já existentes na web. São aplicações produzidas em paralelo a um programa mais complexo, que serevem para utilização do mesmo. Fonte - http://en.wikipedia.org/wiki/Third-party software component

http://facebook.com

http://www.linkedin.com/nhome/

http://foursquare.com/ 
de consumo cultural vão surgindo propiciadas pelas tecnologias do disponível e do descartável, que vão sendo apropriadas por demandas mais heterogêneas, fugazes e personalizadas. 0 conceito de mídia torna-se mais amplo na medida em que a diversidade de aparatos técnicos e a popularização dos mesmos diminuem 0 exclusivismo dos meios de massa. A palavra mídia passa a ser generalizada para se referir também a todos os processos de comunicação mediada por computador (SANTAELLA, 2003).

Com a quebra dos padrões anteriores forma-se uma cultura da mídia em que os consumidores têm possibilidades de escolha entre produtos simbólicos alternativos. Nesse sentido, a cultura da mídia se expande na medida em que 0 conceito de mídia se expande.

Com esses meios é possível que cada vez mais pessoas possam se apropriar de conteúdos reinventando-os. Além de um mesmo conteúdo atingir vários veículos, como rádio, televisão, cinema, blogs, portais, microblogs, entre outros, ele carrega consigo significados diversos que vão atingir variados grupos de interesse. Nesse contexto o consumidor aparece com diferentes papéis com relação a esse conteúdo, já que não é mais um mero receptor podendo apropriar-se das referências dando-lhes novos significados.

Sobre essa crescente interação dos sujeitos com diferentes referências culturais Jenkins (2008) aponta que na cultura da convergência o público consumidor busca suas experiências de entretenimento em qualquer fonte. Nessa lógica ocorre uma transformação nos papéis midiáticos. Não existem mais produtores ou consumidores midiáticos como papéis separados. São participantes que interagem em torno de conteúdos dispersos. E um mesmo conteúdo aparece em diversos suportes nas narrativas transmidiáticas.

Primo (2008a) propõe o conceito de encadeamento midiático para definir o processo em que as pessoas podem buscar notícias em diferentes fontes. 0 autor enfatiza que a mídia tradicional se fortalece com as mídias sociais que geram espaço para 0 debate quanto aos assuntos presentes nos jornais.

Utilizando o conceito de convergência, Silveira (2010), acredita que juntamente com a cultura de convergência ocorrem transformações tecnológicas que produzem novas formas de sociabilidade. Em sua pesquisa o trabalho de Jenkins (2008) é interpretado com ênfase na cultura participativa em que são analisados casos em que o processo ocorre em um modelo de baixo para cima. $0 u$ seja, produtos culturais que são criados pelas indústrias midiáticas reinventados e reinterpretados por seus fãs que acabam gerando novos produtos.

Burgess e Green (2009) sob a mesma ótica realizam uma pesquisa com relação a vídeos mais populares no Youtube ${ }^{5}$ preocupando-se em descobrir uma cultura comum compartilhada e particular desse site, respeitando sua 
complexidade e particularidade. Eles alegam que as categorias estudadas para medir popularidade (categorias de vídeos mais vistos, mais adicionados aos favoritos, mais respondidos e mais comentados) exigem participação do usuário e acreditam que cada interação do público acaba construindo uma versão diferente do Youtube.

Essa ênfase na participação do sujeito na difusão midiática é um dos pontos-chave dessa pesquisa. Considerando a potencialidade na web para difusão de conteúdo midiático entende-se que muitas vezes um sujeito comum torna-se difusor de mídia. Primo (2008b) classifica blogs direcionados na web como micromídia digital. Para 0 autor os blogs podem ser considerados veículos midiáticos uma vez que seu conteúdo é construído dentro de uma lógica de produção em que um público-alvo é visado como audiência. A diferença desses veículos para os de mídia de massa ou de nicho está no processo e custo de produção e em uma audiência bem menor e condensada em assuntos específicos.

0 autor refere-se a blogs produzidos por profissionais que se dedicam a eles com um planejamento, e muitos possuem o blog como principal fonte de renda. Porém, pessoas que não necessariamente estabelecem isso como atividade principal em muitos casos acabam se tornando também geradores de conteúdo midiático com públicos específicos. Esses públicos também podem ser chamados de redes de contatos em sites de redes sociais. Um ator em uma rede social é sempre um nó na teia de conexões humanas (RECUER0, 2009). Sob essa perspectiva cada nó em uma rede social pode ser considerado uma fonte midiática, podendo se tornar um $h u b$ de acordo com o número de conexões.

\section{A representação do sujeito e a cultura da mídia na web}

Turkle (2008) afirma que a cultura digital cria novas maneiras de retrabalhar o pessoal. Em outra pesquisa, Turkle (1997) questiona a ideia de que a vida virtual não é real. Apesar de trabalhar com identidades construídas em ambientes de jogos RPG on-line, para ela existe uma vida digital e 0 que ela chama de "o resto da vida", que é real e cada vez conversa mais com as interações off-line.

Os processos de representação que ocorrem em espaços pessoais são comentados por diversos autores. Para Mazur e Kozarian (2001) os blogs são usados mais para autoapresentação do que para interação. Os blogs dão a seus proprietários uma oportunidade de controlar sua persona pública através da escrita e gerenciamento de informações pessoais. No entanto, assume-se nesse trabalho que a representação também é considerada uma forma de interação. Porque ela pode ser construída através dos processos interativos.

Não é a toa que muitos autores colocam a criação de redes de contato como um dos critérios para formar identidade. Walker (2000) aponta que as 
informações pessoais podem ser apresentadas como listas, narrativas e afiliações e apresentam eficientemente a identidade do sujeito. Boyd e Ellison (2007) apontam que os perfis dos sites de redes sociais são representações da identidade do sujeito por trazerem traços de suas características. 0 sujeito pode ser identificado por eles através dos conteúdos que ele mesmo adiciona por afinidade, como textos, fotos ou vídeos, e conteúdos postados por seus amigos como depoimentos ou comentários. Um sujeito escolhe as informações de seu próprio perfil baseando-se nos perfis de seus contatos.

Segundo Amaral (2009), um perfil em sites de redes sociais pode ser construído através de subjetivação e consumo. Ela aponta que no ciberespaço há um universo de consumo midiático com apropriações de bens simbólicos materiais e imateriais. Assim, nos perfis existem afinidades a conteúdos e bens de consumo, sendo que essas afinidades também contribuem para a formação de identidade do sujeito. Essas informações que incorporam a representação do indivíduo podem ser de cunho midiático e uma vez difundidos tornam 0 sujeito um disseminador de referências da comunicação.

Quando um sujeito posta um conteúdo de seu interesse, este passa a fazer parte de sua rede de representações que estão ligadas a sua personalidade. No exemplo da figura 1, 0 sujeito referencia um assunto que faz parte de seus gostos e interesses e pode contribuir para a formação de sua identidade. Ele com certeza agrega valor à representação que esse indivíduo exerce para com seus contatos, já que faz parte de seus processos interativos. Além disso, esse conteúdo é de cunho midiático, pois se refere a um vídeo com uma notícia no site da $\mathrm{NBC}^{6}$ (National Broadcasting Company) inclusive com conteúdo publicitário associado.

A interação ajuda a formar identidade, pois qualquer conteúdo postado será parte da pessoa que a está postando. Assumindo essa proposta, a representação do sujeito não ocorre somente nos perfis dos sites de redes sociais, mas em toda a extensão de interação que o sujeito cria. Na web esses conteúdos atingem 0 alcance de todos os grupos experienciados pelo autor.

No Facebook, por exemplo, existe a funcionalidade newsfeed que expõe no perfil de cada um todas as atualizações de seus contatos. Com essa funcionalidade 0 Facebook foi um dos pioneiros no tipo de configuração mais utilizado em sites de relacionamento atualmente, aquele em que as informações pessoais do sujeito que sugerem suas identificações e interesses ultrapassam os limites do perfil. Não é mais necessário ir até 0 contato para visualizar informações sobre essa pessoa, pois elas invadem os perfis dos outros criando trocas mais dinâmicas. Assim, o sujeito quando cria um perfil pode estar se tornando coautor do perfil de seus contatos que serão influenciados por ele. 
Figura 1- Exemplo de conteúdo midiático relacionado com a representação do sujeito

(d)ericschmidt

Eric Schmidt.

\section{Fun story on Google Cars \\ http://goo.gl/RP26 its wild to be in a car that is driving itself. Note the wisdom of the taxi driver at the end.}

12 Oct vis web Ll Fanorte ta Retweet hi Rieply

Retweeted by route 2 chaos and 89 others

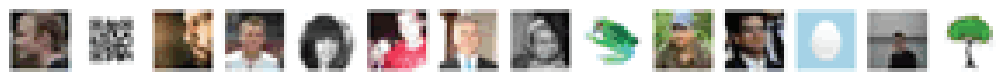

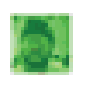

\section{Tweets containing Google Cars}

achtungae on Achtung Aeon

Google cars nabbed email addresses and passwords -

Search giant Google admitted last week that its fleet of Street

V... http://ow.ly/19Ge6c

16 minutes ago

\section{SenseiWuzi Wuzimu}

Google cars nabbed email addresses and passwords - tech 28 October 2010 - New Scientist http://bit.ly/aEyNgJ

1 hour ago

Fonte: SCHMIDT, 2010.

\section{Procedimentos metodológicos}

Nessa pesquisa pretende-se investigar os possíveis

papéis que um sujeito pode ter com relação ao

conteúdo presente em um site de redes sociais.

Por ser usado por uma parecela significativa da população, o Twitter reune postagens com assuntos de áreas variadas, tornando-se um espaço em que o sujeito pode ser considerado um $h u b$ de referências. Por ter um $\mathrm{API}^{7}$ aberto, outras empresas podem criar softwares que por um software para que suas funcionalidades possam ser utilizadas por programas aplicativos. API, é uma parte do código de um software, e através da manipulação do mesmo é possível criar pequenos softwares compatíveis com o inicial, que se tornam apêndices do mesmo. Este apêndice é chamado widget, um pequeno aplicativo com uma função específica inserido em outro programa maior que ele. Fonte: http://pt.wikipedia.org/wiki/API 
reorganizem as postagens do Twitter, dando a elas novos significados. É preciso frisar que o foco dessa pesquisa está nas diferentes formas que um indivíduo tem de se relacionar com o conteúdo e como isso afeta a rede. Acredita-se que essas ferramentas enriquecem as interações, porém 0 foco da pesquisa não é no desenvolvimento técnico.

Realizou-se uma observação do conteúdo proveniente do site de microblog Twitter e como ele aparece em aplicativos como Flipboard, Paper.li e mais amplamente o Tweetdeck que são utilizados para visualização de informações disponiveis no site e possibilidades de participação.
Após a observação realizou-se um questionário sobre relação dos sujeitos com o conteúdo do Twitter através do Tweetdeck dividido em três partes. A primeira tem perguntas em relação à forma como as pessoas organizam a informação que recebem. A segunda traz perguntas sobre como as pessoas interpretam postagens daqueles que seguem, ou seja, qual o nível de importância que dão para as informações, e se selecionam contatos ou tipos de conteúdos mais e menos importantes. A terceira parte é com relação ao sujeito como participante ativo que posta contribuições ao Twitter. As perguntas questionam sobre a natureza das informações, de onde elas provêm e se 0 usuário foi 0 autor ou não.

Quadro 1 - Questões do questionário sobre a utilização do Tweetdeck

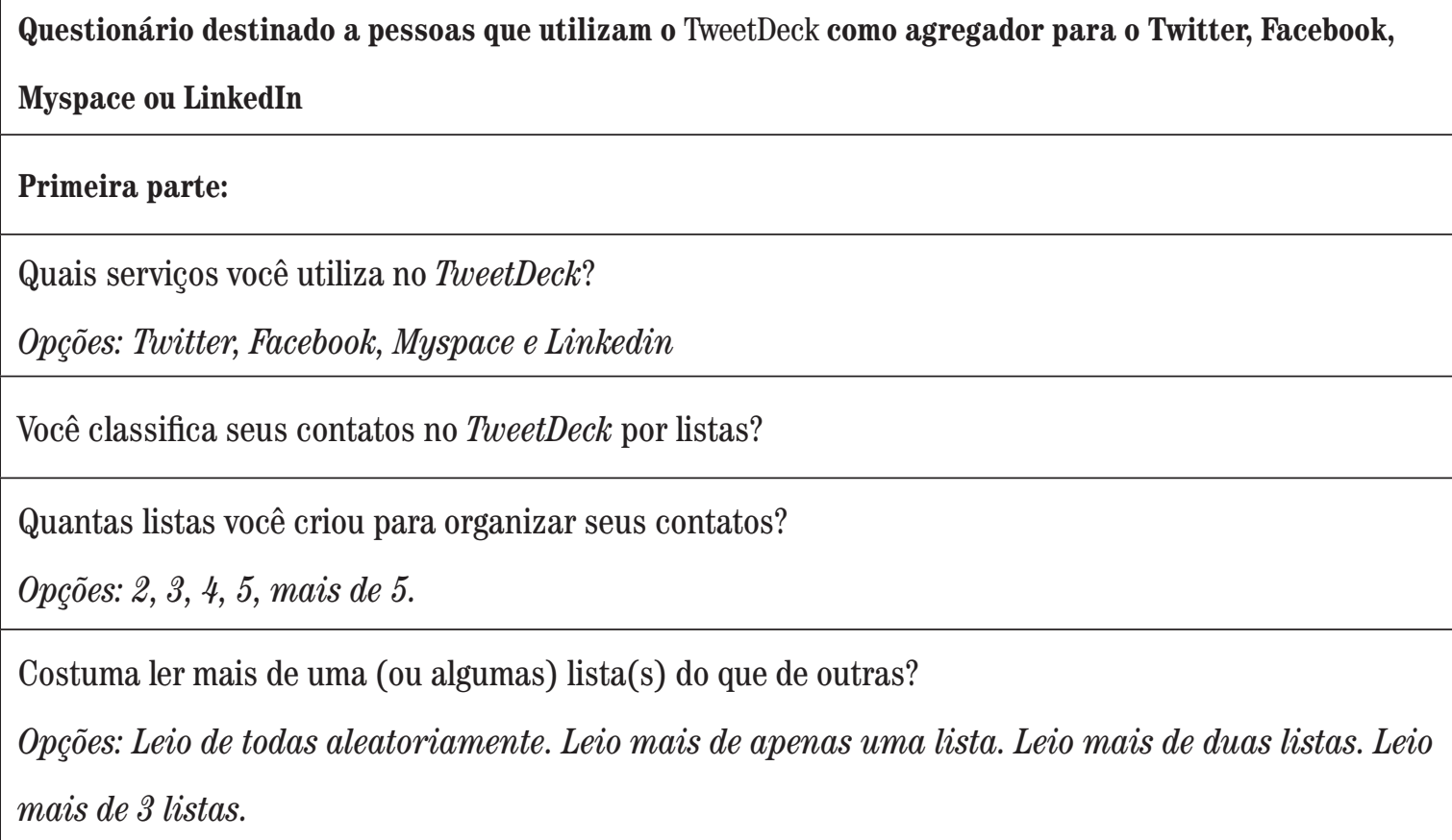




\section{Segunda parte:}

Em média em quantos links postados por contatos você clica por dia pelo TweetDeck?

Opções: Mais de 10 por dia. De 05 a 09 por dia. De 01 a 04 por dia. De 10 a 15 por semana. De 05 a 09 por semana. De 01 a 04 por semana. Menos de 01 por semana. Nunca clico.

De quais serviços são os links que você costuma clicar?

Opções: Twitter, Facebook, Myspace, Linkedin, nenhum.

Desses links que são clicados são de contatos variados ou alguns poucos?

Opções: variados. De 10 a 15 contatos. De 08 a 10 contatos. De 04 a 07 contatos. De 01 a 03 contatos.

Qual tipo de conteúdo lhe chama mais atenção para clicar, dentre os listados abaixo?

Opções: Textos de blogs. Textos de sites de notícias. Fotos mostrando fatos. Imagens curiosas. Video mostrando fatos. Videos curiosos.

\section{Terceira parte:}

Você realiza postagens através do TweetDeck?

Por quais serviços?

Opções: Twitter, Facebook, Myspace, Linkedin.

Que tipo de conteúdo você posta normalmente?

Divulgação de conteúdo de produção própria.

Opções: blog próprio, portifólio próprio, postagem de texto próprio, outros.

Com que frequência?

Opções: mais de 10 vezes por semana. De 05 a 09 vezes por semana. De 01 a 04 vezes por semana.

\section{Compartilha ou divulga texto postado por seus contatos?}

De quais serviços?

Opções: Twitter, Facebook, Myspace, Linkedin.

Com que frequência?

Opções: mais de 15 vezes por semana. De 10 a 14 vezes por semana. De 05 a 09 vezes por semana. De 01 a 04 vezes por semana. 
Os resultados obtidos serão apresentados juntamente com a análise.

As considerações apresentadas são feitas com base nas interações que as pessoas realizam no Twitter. No questionário respondido por 167 pessoas $100 \%$ delas afirmou realizar atualizações no Twitter pelo Tweetdeck. Dessas, 33\% pessoas utilizam o Facebook através do Tweetdeck, apenas $4 \%$ o MySpace e 11\% o Linkedin.

\section{Tweetdeck: 0 conteúdo centrado no sujeito}

Serviços destinados a diferentes formas de interação com a informação brotam diariamente na web 2.0 ou novos aplicativos para plataformas móveis como Iphone, Ipad e Android. Muitas pessoas participam de diferentes sites de redes sociais gerando nesses espaços informações provenientes de seus processos interativos.

Tornaram-se comuns os aplicativos do tipo mashups que incorporam a informação compartilhada nas redes e a reorganiza dando novos significados.

Essas plataformas foram se desenvolvendo para tornar mais prática a manipulação de dinâmicas sociais criadas no Twitter pelos próprios usuários. Alguns desses aplicativos acabam criando novas formas de organizar a disposição de informações. De modo que é possível criar até mesmo revistas com o conteúdo postado por contatos. No Paper.II é um é possível criar um site com diagramação de jornal a partir de filtros pré-definidos. 0s jornais podem trazer postagens de um usuário do Twitter mais as dos seus seguidos, ou de uma hashtag específica ou de uma lista.

Figura 2 - Interface criada com os filtros definidos pelo usuário com diagramação de jornal.

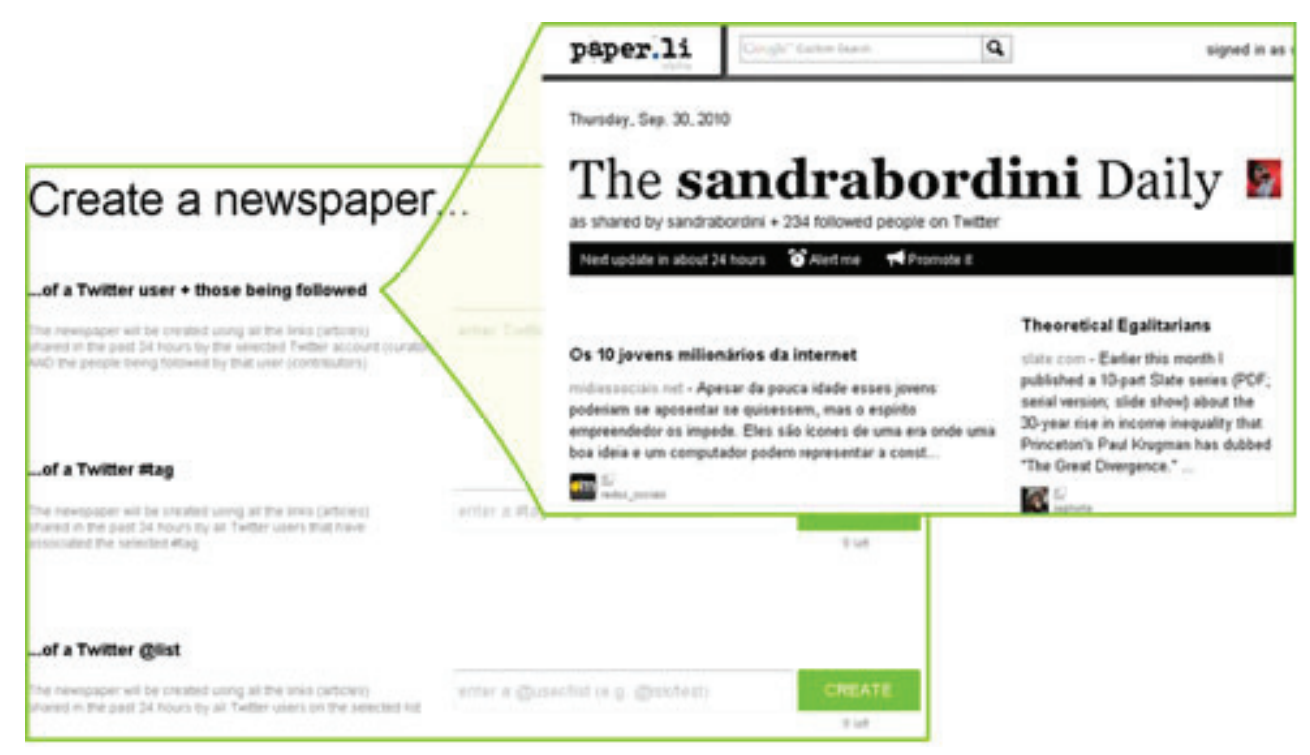


0 Flipboard, ${ }^{9}$ disponível apenas para Ipad, é um aplicativo usado para a mesma ideia com mais opções de personalização da interface. 0 presente objeto, o Tweetdeck pode ser usado para interações em sites de redes sociais. A diferença do Tweetdck ${ }^{10}$ para os citados anteriormente é que através dele um sujeito pode realizar atualizações próprias bem como ler as atualizações de seus contatos, enquanto outros permitem somente leitura. Os serviços que podem ser utilizados no Tweetdeck são Twitter, Facebook, MySpace, Linkedin, Google Buzz e o Foursquare. Cada serviço é apresentado em uma lista na interface, com várias opções de personalização.

Além dos serviços, o programa possibilita que sejam criadas listas mais específicas. Com relação ao Twitter, por exemplo, é possível criar listas com mentions, ou seja todas as postagens que referenciam o nome do usuário, ou direct messages, as mensagens particulares, ou mesmo uma listagem com os seguidores mais recentes. Pode-se criar listas por palavras-chave ou hashtag realizando-se uma busca pelo assunto desejado. Também é possível agrupar os contatos seguidos por assuntos de interesse em cada lista.

Figura 3 - Interface principal do Tweetdeck com as listas selecionadas.

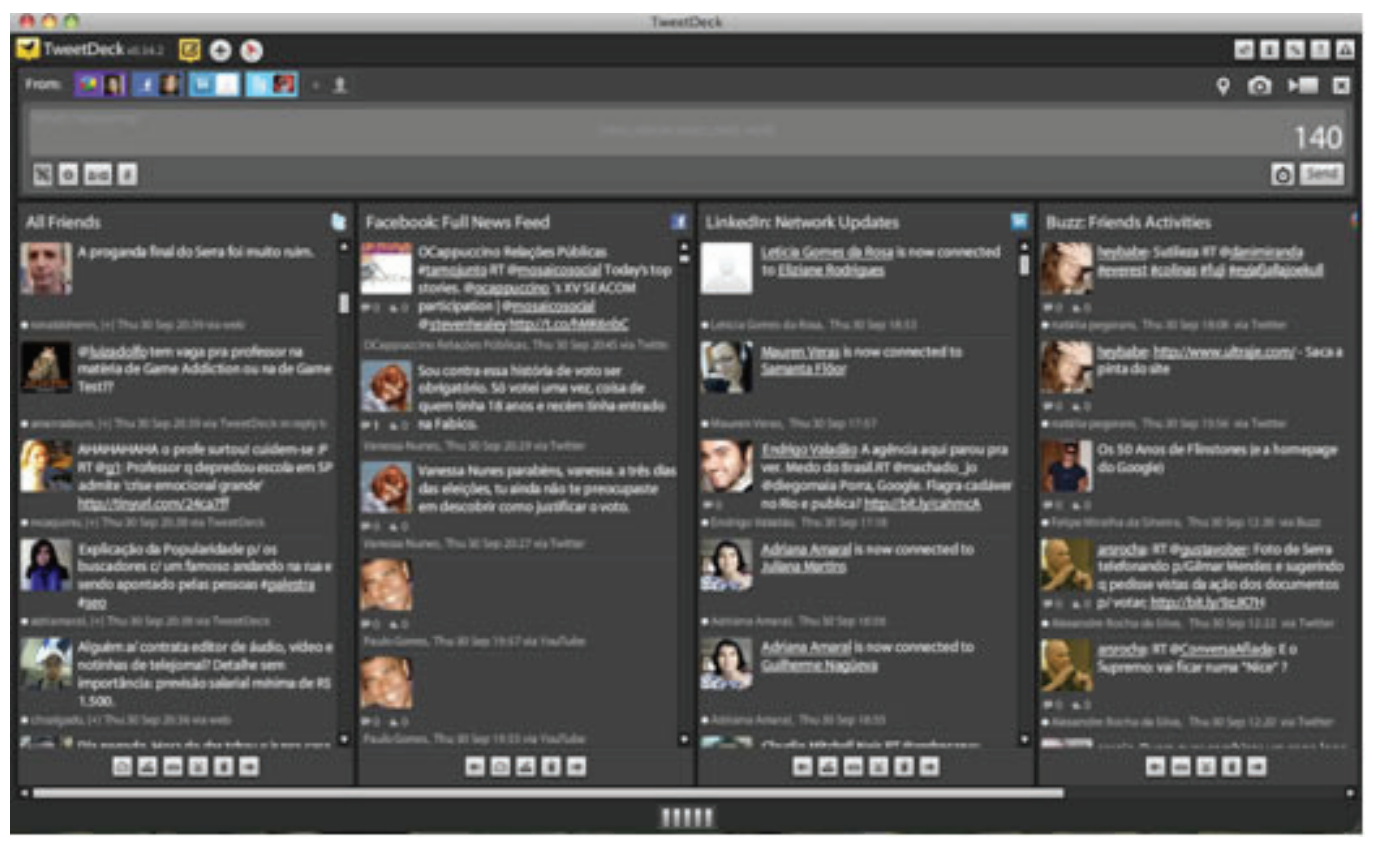

Fonte: http://tweetdeck.com.

http://www.flipboard.com/

Existem outros aplicativos usados para dinamizar as trocas no Twitter tais como o Echofon, o Seesmic, o Twitterfeed, 0 Hootsuite, o CoTweet, o Twitterific, entre outros. 
Essas dinâmicas sociais e as relações que os sujeitos estabelecem com os conteúdos, colocam os indivíduos em uma nova posição com relação ao conteúdo midiático. A seguir apresenta-se uma proposta de papéis que 0 sujeito representa.

\section{0 sujeito como produtor, compartilhador e leitor de conteúdo midiático nas redes sociais}

A cultura compartilhada na internet é transparente e participativa. Nesse processo as pessoas podem interagir com os conteúdos midiáticos tornando-0s seus próprios. Na cultura da mídia as pessoas podem escolher entre produtos simbólicos alternativos.

Essa realidade é dinâmica e a relação entre absorção, processamento e reenvio é fugaz assim como as necessidades dos sujeitos por novas informações.

As referências adicionadas por afinidades fazem parte da representação de cada indivíduo. 0s conteúdos podem ser midiáticos se os sujeitos formam microcanais de comunicação com uma audiência visada. Quando um sujeito posta um conteúdo midiático, como referente a um filme, ou uma série de TV em seu perfil, ou mesmo em suas conversações em fóruns ou na timeline do Twitter, ele está associando esse conteúdo com sua representação. Seus grupos de amigos, os quais visualizam seu perfil ou estabelecem consigo conversações é a audiência visada. Esses contatos ainda podem participar de diferentes contextos, ou seja, diferentes grupos de interesse, que vão atribuir significados diferentes aos conteúdos com os quais interagem.

Cada sujeito forma suas conexões com base em seus interesses de forma que a informação compartilhada está no contexto. No entanto, um mesmo sujeito tem vários interesses conectandose a diferentes pessoas e tomando parte em vários grupos. Assim, muitas vezes a informação que compartilha ou produz traz processamento de influências diversas. Sendo que as próprias experiências do sujeito em cada grupo pode também reproduzir referências. Existe uma rede de interesses que se mesclam, em que bens simbólicos são repassados e reinterpretados adquirindo novos significados. Nesse processo, forma-se uma rede de recomendações diretas e indiretas.

Existe, portanto, mais de uma forma de apropriação e processamento de conteúdos. Um sujeito não necessariamente torna um conteúdo seu próprio quando o compartilha. Quando vemos um conteúdo que nos foi enviado por um contato, a princípio 0 atribuímos a ele. Porém, muitas vezes é um link que foi repassado, ou ainda uma produção que traz referências diversas resultadas em um mashup. Nesse sentido, o que se quer avaliar são as possibilidades de se relacionar com os diferentes conteúdos midiáticos que cada sujeito tem.

Busca-se, portanto, elaborar os caminhos possíveis das novas tendências midiáticas em que cada sujeito tem uma participação cada vez mais relevante. Esses papéis, apesar de tratados aqui 
separadamente, são acumuláveis, de forma que um mesmo sujeito pode exercer os três ao mesmo tempo ou alternadamente.

\subsection{0 produtor de conteúdo}

Quando foi questionado aos participantes da pesquisa quantitativa sobre a utilização do Tweetdeck quanto ao tipo de conteúdo que eles postam diariamente a maioria das pessoas afirma que posta conteúdo produzido por si próprio.

Dentre as 167 pessoas, 74 afirmaram que postam divulgando conteúdo de blog próprio, 35 marcaram que postam divulgação de portifólio próprio e 102 afirmam que postam texto próprio. Ou seja, mesmo quando o conteúdo é apenas divulgado no ambiente citado, trata-se de um link para um espaço pessoal onde o conteúdo produzido é disponibilizado. Mesmo assim, 102 pessoas apontam que postam textos produzidos para 0 próprio ambiente, no caso o Twitter. Assim, mesmo sendo um texto curto as pessoas expressam ali sua opinião por esse conteúdo. Mesmo que essas 102 pessoas estejam apenas comentando postagens alheias, a expressão de sua opinião é também uma produção de conteúdo. Esse ponto reforça a importância de que 0 sujeito exerça os papéis de leitor e compartilhador para tornar-se produtor, como será discutido nos pontos seguintes. Ainda 37 pessoas colocam que postam conteúdo de outros tipos, porém de produção própria.

Com essa proposta é possível ressaltar que apesar de haverem críticas quanto a uma redução na capacidade dos sujeitos de produzirem conteúdo próprio, os interagentes das mídias sociais possuem um caráter expressivo bastante forte e valorizam muito o espaço que têm para divulgar sua opinião. Essa realidade confirma-se quando é perguntada a frequência com a qual os conteúdos são postados. Nas respostas 95 pessoas afirmam que postam mais de 10 vezes por semana.

Figura 4 - Tipos de conteúdos de produção própria postados pelo Tweetdeck

\section{Shering self-produced content}

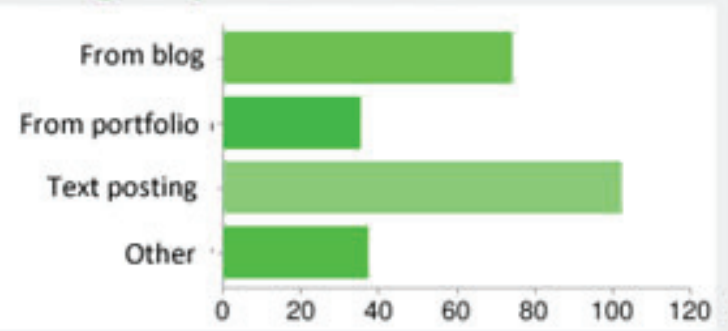

$\begin{array}{lrr}\text { From blog } & 74 & 49 \% \\ \text { From portfolio } & 35 & 23 \% \\ \text { Text posting } & 102 & 68 \% \\ \text { Other } & 37 & 25 \% \\ & \\ \text { People may select more than one } \\ \text { checkbox, so percentages may add up } \\ \text { to more than } 100 \% .\end{array}$




\section{Figura 5 - Frequência com que as pessoas postam conteúdos de produção própria pelo Tweetdeck}

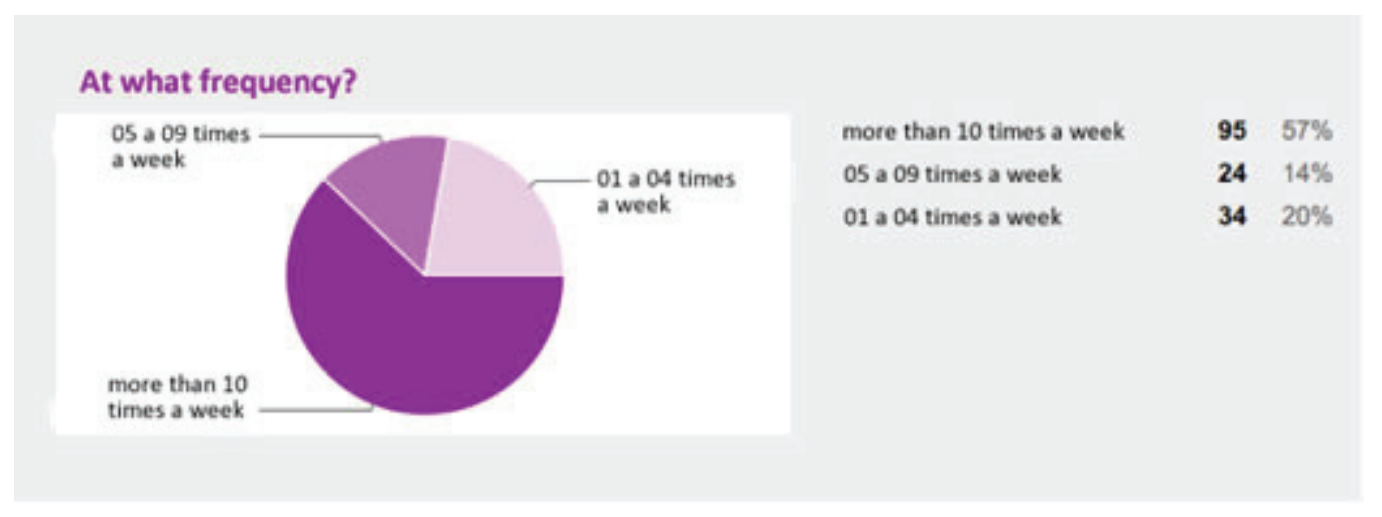

Esse produtor é, portanto, o sujeito que desenvolve conteúdo midiático a partir de sua própria percepção. Normalmente 0 conteúdo produzido traz temas da mídia que se mesclam com 0 interesse do indivíduo. Nesse sentido, reforça-se a reconfiguração do "quem" e do "como" uma referência cultural é elaborada (BENKLER, 2006). Ou seja, um indivíduo comum pode tornar-se produtor e disseminador cultural. Ou seja, essa parcela utiliza-se dos novos meios de produção e divulgação para atingirem uma participação significativa no que tange à produção de conteúdos midiáticos.

Esse talvez seja o papel de maior inovação desse novo período em que se desenvolvem os novos meios de expressão e divulgação cultural. Muitos autores apontam que os sujeitos não são mais receptores passivos. Eles podem colaborar com o conteúdo, reprocessá-lo e torná-lo seu próprio. 0 que é importante ressaltar é a importância do grupo, ou dos grupos em que o sujeito está inserido nesse processo, pois esses grupos de interesse serão fundamentais para a produção desse sujeito, uma vez que o produtor desenvolve conteúdo utilizando como base as referências às quais tem acesso. Naturalmente essas referências já são resultado de uma escolha de redes de contatos que tratam de materiais relevantes para esse sujeito.

Ou seja, para se tornar produtor o indivíduo precisa ter suas referências. Pois ninguém produz conteúdo fora de um contexto cultural, como aponta Benkler (2006). Esse conteúdo produzido relaciona-se com a identidade de cada um, justamente por trazerem fragmentos de referências que interessam ao sujeito e fazerem parte de quem ele é. É o sujeito que antes de produtor torna-se compartilhador e, antes mesmo, leitor, pois estes irão selecionar os conteúdos que lhe são mais significativos para associar com suas experiências. 


\subsection{0 compartilhador de conteúdo}

É pertinente iniciar a análise sobre 0 compartilhador apontando que dentre as 167 pessoas questionadas sobre a participação no Tweetdeck, 157 delas, ou seja 94\% afirmam que compartilham postagens de seus contatos. É inegável, portanto, a presença desse papel nas conexões que se formam nas mídias sociais. $\mathrm{Na}$ questão seguinte, perguntou-se quais os serviços dos quais as pessoas compartilham conteúdo, sendo que 158 selecionaram o Twitter, 34 marcaram o Facebook, 5 o MySpace e 6 o Linkedin.

Quanto a frequência de compartilhamento, 82 das pessoas dizem que repassam conteúdo de seus contatos mais de 15 vezes por semana, 21 selecionam a opção de 10 a 14 vezes por semana, 43 dizem que divulgam de 5 a 9 vezes por semana e 13 marcam que repassam de 1 a 4 vezes por semana. Assim, das 159 pessoas que responderam essa questão todas elas compartilham conteúdo pelo menos uma vez por semana, sendo que a maioria (82 pessoas) tem um alto índice de compartilhamento, repassando informações de seus contatos mais de 15 vezes por semana.

0 papel do compartilhador é o mais importante no que diz respeito à difusão da informação na rede, pois boa parte da participação na web se dá por conta dessa prática realizada pelos sujeitos. Basta comparar os números acima com os números referentes à frequência com a qual os sujeitos postam conteúdos de produção própria (Figura 6). Apesar de ser alta, essa ainda é significativamente menor do que a quantidade de vezes que os sujeitos compartilham o que foi postado por seus contatos. Afinal, mesmo quando exercendo o papel de produtor, um sujeito não dará a devida relevância para seu conteúdo se este não for compartilhado, clicado e lido. Forma-se uma rede de recomendações diretas e indiretas em que aqueles que são mais referenciados adquirem maior reputação. Nesse processo o papel de compartilhador do sujeito é imprescindível para que se crie uma rede de referências reconstruídas.

Figura 6 - Frequência de compartilhamento de conteúdos

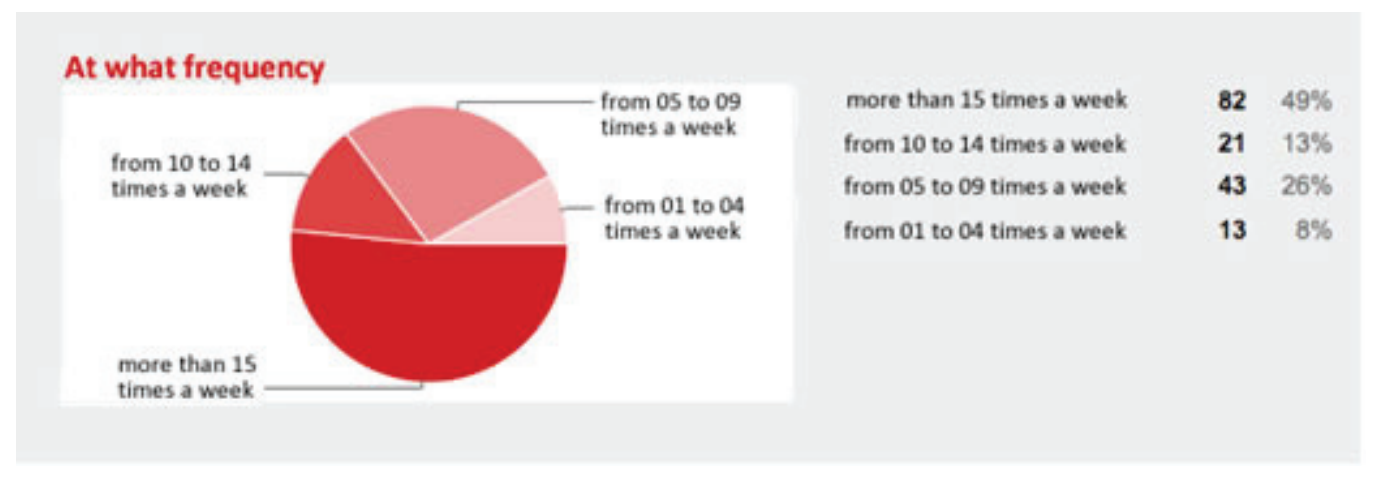


0 compartilhador pode não ser 0 autor do conteúdo, mas em muitos casos recebe crédito por ele, já que nessa dinâmica o status de compartilhador também é muito importante.

Mas o que se observa é que quando um indivíduo referencia um conteúdo ele se apropria do mesmo, uma vez que para seus contatos, o conteúdo foi proveniente do indivíduo já que foi através dele que se teve acesso. Um exemplo claro dessa realidade é a prática de retweet no Twitter. Um sujeito que "retuita" alguém está se apropriando do que já foi dito por outra pessoa. E quando um post de retweet é novamente "retuitado" é necessário que a fonte através da qual se teve acesso ao post (ou seja, a pessoa que "retuitou" primeiro) seja referenciada, e isso faz parte do código de valores que se forma nesse ambiente. Nesse sentido, o compartilhador ganha status de autor tornando-se obrigatória a sua citação.

Tanto o produtor quanto o compartilhador ao assimilarem um conteúdo e torná-lo seu estão selecionando informações relevantes para si. Considerando que suas interações são formadas em grupos de interesse dos quais faz parte cabe afirmar que essas informações são também relevantes para seus contatos. Esses contatos são, portanto, aqueles que o compartilhador deseja atingir ao disseminar uma mensagem. Tanto seus gostos quanto os das pessoas com quem realiza suas trocas são formados através de escolhas que esse sujeito realiza, e que estão relacionados aos seus processos de formação de identidade.
Essas referências podem ser provenientes da mídia industrial, mas o fato de um sujeito comum se apropriar delas e comunicá-las a seus contatos gera uma maior participação em torno do assunto.

\subsection{0 leitor interagente}

0 leitor é 0 sujeito que pode aproveitar 0 trabalho feito por seus contatos de selecionar, produzir e compartilhar informações. E cada vez mais criadores de aplicativos percebem isso e desenvolvem novas possibilidades de transformar esses conteúdos em espaços onde a diagramação e a organização da informação são semelhante a veículos midiáticos. 0 leitor também está inserido em grupos de interesse e vai buscar e selecionar os conteúdos que lhe são relevantes.

Se podemos criar jornais ou revistas através do que é postado por contatos no Twitter estamos, de certa forma, seguindo uma tradição editorial. Porém, nesse processo a pessoa escolhe seus "redatores" um por um. De forma que a própria audiência torna-se editora de suas notícias diárias, selecionando os assuntos de seu interesse e aqueles que escreverão sobre eles.

Quanto à organização de conteúdo por parte do leitor no Tweetdeck, a maioria dos pesquisados (106) afirma que não utiliza listas, apesar de uma parcela significativa (61) responder que utiliza. Significa que a maioria das pessoas não tem necessidade de classificar os seus contatos, talvez porque prefira ter todas as suas referências misturadas, mesmo abordando temas diversos. 


\section{Do you classify your contacts using lists at Tweetdeck?}

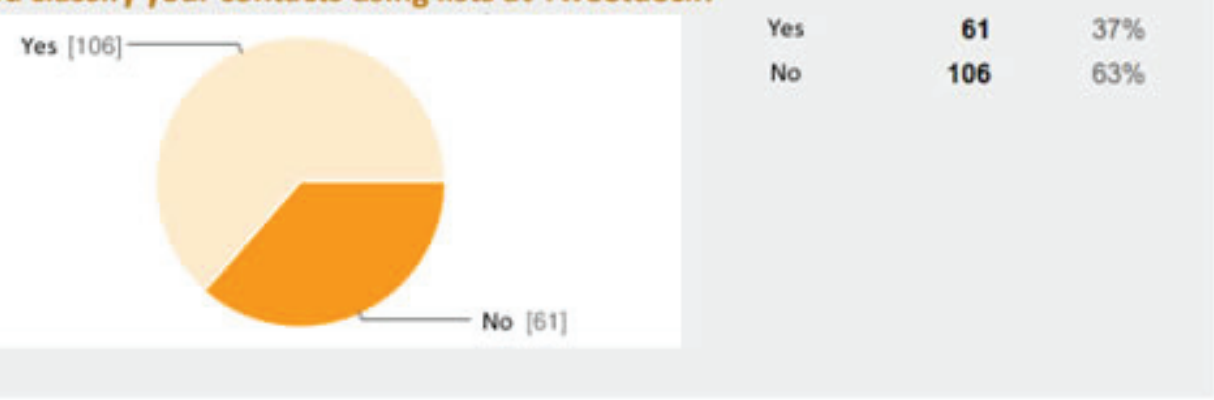

A própria seleção de contatos que uma

pessoa realiza no Twitter já é uma filtragem de informações. Criar listas é uma forma de organizar esses contatos por temas. É um esforço para classificar o que alguns aplicativos, como o Paper.li fazem automaticamente. Dessa forma, o leitor atribui relevância aos conteúdos que seus contatos postam organizando em áreas de interesse. Essas listas, no Tweetdeck também podem ser utilizadas para acompanhar palavras específicas, assim quando houver algum evento cujos acontecimentos sejam importantes para 0 sujeito esse pode criar uma lista com a palavra referente. É interessante, pois torna possível que o sujeito acompanhe eventos de menor importância que não seriam noticiados na grande mídia.

Quando foi perguntado sobre quantas listas os usuários criam para classificar os seus contatos, 20 pessoas selecionaram a opção de 2 listas, 23 pessoas marcaram 3 listas, 10 pessoas marcaram a opção de 4 listas, 6 pessoas marcaram que organizam por 5 listas e 9 pessoas marcaram que organizam em mais de 5 listas.
Também foi perguntado quanto à utilização dessas listas, buscando-se saber se os participantes costumam ler mais de uma (ou algumas) lista(s) do que das outras. Dentre as que separam seus contatos por listas, $24 \%$ marcaram que leem de todas aleatoriamente, $10 \%$ marcaram que leem apenas de uma lista, $5 \%$ marcaram que leem de mais de 2 listas e 4\% marcaram que leem de mais de 3 listas (57\% não respondeu essa questão por não separarem seus contatos por listas).

Com esses dados é possível observar que mesmo as pessoas que criam listas, em sua maioria dividem em no máximo três, e ainda afirmam (40 dentre as 61 que separam por listas) que leem referências de todas elas aleatoriamente. Isso mostra que a seleção que 0 sujeito realiza é feita sem muita organização prévia. 0 sujeito encontra aquele conteúdo e apropria o que é mais interessante na hora em que ele está sendo postado. Isso é confirmado pela pesquisa quanto ao número de clics, já que a maioria dos participantes (97) clica em mais de 10 links por dia e outros 46 marcam em 5 a 9 por dia. E $69 \%$ do total clica em links de contatos 
Figura 8 - Hábitos de leitura das listas criadas por cada sujeito no Tweetdeck

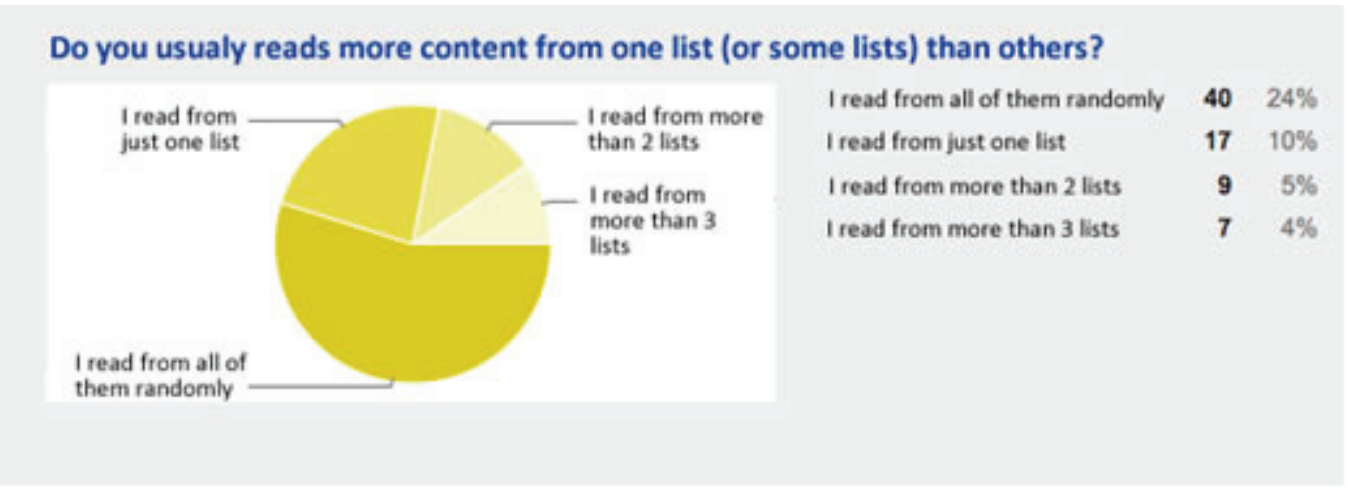

variados. Talvez a principal organização seja feita pela seleção de contatos, que ocorre, na maioria dos casos, naturalmente, pelas afinidades e interesses.

Em outra questão pergunta-se sobre qual tipo de conteúdo chama mais atenção para ser clicado, e foi dada uma listagem de opções. Assim, 136 pessoas escolheram a opção textos de blogs, 128 pessoas marcaram que clicam em textos de sites de notícias, 99 pessoas disseram que clicam em links para fotos mostrando fatos. Outras 99 também marcaram que clicam em imagens curiosas, 66 escolheram a opção vídeos mostrando fatos e 67 selecionaram a opção vídeos curiosos. Assim, o papel de leitor também não é de cunho passivo como se poderia imaginar. Esse leitor não se assemelha ao receptor da mídia de massa. Trata-se, portanto, de um leitor interagente que escolhe suas leituras. E mais do que isso, seleciona aqueles que irão realizar os conteúdos que ele lê através da rede. 0 conteúdo dificilmente atinge 0 sujeito por acaso, pois faz parte de um processo previamente selecionado.

Figura 9 - Tipos de conteúdos mais clicados pelos participantes da pesquisa

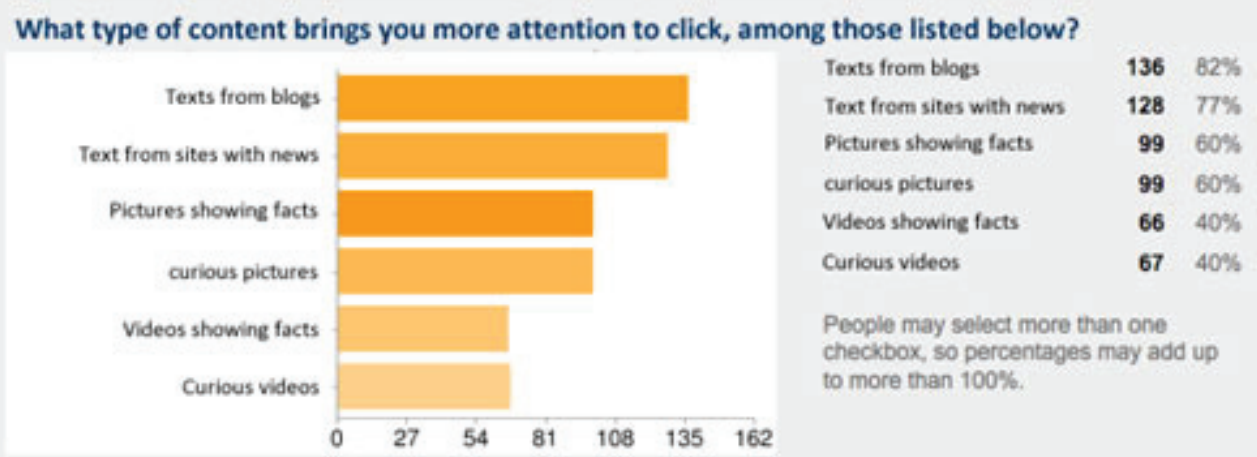




\section{Considerações finais}

Novos serviços inspiram novas formas de se comunicar na web. Assim como as práticas interativas inspiram novas funcionalidades ou serviços na web. 0 próprio Twitter toma novas proporções com a ação dos sujeitos e seus papéis. As novas formas de interação e compartilhamento de conteúdos em rede tornam possível uma reinterpretação do sujeito com relação à mídia. A participação do mesmo torna-se cada vez mais fundamental para a difusão informacional.

Este artigo traz as reflexões iniciais de uma pesquisa que ainda será ampliada. Pressupõe-se que no percurso novos papéis do sujeito surgirão para uma compreensão mais ampla do objeto.

\section{Referências}

AMARAL, A. Plataformas de música online: práticas de comunicação e consumo nos perfis. In: TRIVINHO, E.; CAZELOTO, E. (Org.). A cibercultura e seu espelho. São Paulo: ABCiber, 2009. Disponível em < http:// abciber.org/publicacoes/livro1/rosto/> . Acesso em: 10 set. 2010.

\section{BENKLER, Y. The Wealth of Networks.}

New Haven: Yale University Press, 2006.

BOYD, Danah M.; ELLISON, Nicole B. Social Network Sites: Definition, History, and Scholarship. Journal of ComputerMediated Communication. v. 13, n. 1 , 2007. p. 210-230. Disponível em: < http:// www.blackwell-synergy.com/doi/pdf/10.1111 /j.1083-6101.2007.00393.x> Acesso em: 29 maio. 2008.

\section{BURGESS, J.; GREEN, J. Youtube e a}

Revolução Digital. São Paulo: Aleph, 2009. CASTELLS, M. Sociedade em rede: era da informação. São Paulo: Paz e Terra, 1999. JAVA, A. et al. Why we twitter: understanding microblogging usage and communities. In: WebKDD. I SNA-KDD 2007 workshop on $\mathrm{Web}$ mining and social network analysis. 9., 2007. San Jose. Anais... San Jose, 2007. Disponível em: < http://portal.acm.org/citation. cfm?id=1348556 > . Acesso em: 1 jul. 2008.

JENKINS, H. Cultura da convergência. São Paulo: Aleph, 2008.

MAIA, Marcelo; ALMEIDA, Jussara; ALMEIDA, Virgílio. Identifying User Behavior in Online Social Networks. In: EUROPEAN CONFERENCE ON COMPUTER SYSTEMS, 2008. Glasgow. Anais... Glasgow, 2008.

MAZUR, E.; KOZARIAN, L. Self-Presentation and Interaction in Blogs of Adolescents and Young Emerging Adults. Jan. 2010. Disponível em < http://jar.sagepub.com/ content/25/1/124> Acesso em: 2 set. 2010. PRIMO, Alex. A cobertura e o debate público sobre os casos Madeleine e Isabella: encadeamento midiático de blogs, Twitter e mídia massiva. Galáxia, v. 16, 2008a. 
PRIM0, Alex. Interney Blogs como micromídia

digital: elementos para 0 estudo do encadeamento

midiático. In: ENCONTRO ANUAL DE

ASSOCIAÇÃO NACIONAL DOS PROGRAMAS DE

PÓS-GRADUAÇÃO EM COMUNICAÇÃO, 17., 2008,

São Paulo. Anais..., São Paulo: COMPÓS, 2008b.

p. 1-17.

RECUERO, R. Redes sociais na internet. Porto

Alegre: Sulina, 2009.

SANTAELLA, Lucia. Culturas e artes do pós-

humano: da cultura das mídias à cibercultura.

São Paulo: Paulus, 2003.

SCHMIDT, Eric. Fun story on Google cars.

2010. Disponível em: < http://twitter.com/\#!/

ericschmidt $>$.

SILVEIRA, Stefanie. A cultura da convergência e

os fãs de Star Wars: um estudo sobre o conselho

Jedi RS. 2010. xxx f. Dissertação (Mestrado

em Comunicação e Informação) -Faculdade de

Biblioteconomia e Comunicação, Universidade

Federal do Rio Grande do Sul, Porto Alegre, 2010.

TURKLE, Sherry. Inner History. In: TURKLE,

Sherry. (Org.). The Inner History of Devices.

Cambridge: The MIT Press, 2008.

TURKLE, S. La Vida en la Pantalla: la

construcción de la identidad en la era de Internet.

Barcelona: Paidós Ibérica, S. A., 1997.

WALKER, Katherine. "It`s difficult to Hide it":

The Presentation of Self on Internet Home Pages.

Qualitative Sociology Journal, v. 23, n. 1, mar.
2000. Disponível em: < http://www.springerlink.

com/content/v7176304855757n4/> . Acesso em: 10 out. 2008. 


\section{The Roles of the Subject in relation to Media Contents in Tweetdeck: the producer, the disseminator and the reader}

\section{Abstract:}

The present article investigates the roles of the subject in relation to the media contents of the social networks, and also performs a survey on Tweetdeck exchanges among Twitter users. We propose that the individual internet user is a media disseminator, since the dynamics of referential exchanges in the web is interpreted from his or her very perspective. A user's affinities build his or her personal profile. As well as his or her online interactions provide the user with identity, also being those interactions relevant content for the contacts he or she establishes within groups of interest. In this research, we also approach concepts on culture, media and presentation, and perform a quantitative research regarding information absorption and processing practices in Tweetdeck. The article concludes that there are three possible roles for the subject in relation to the media content: producer, disseminator and reader.

\section{Keywords:}

Subject roles. Representation. Media Contents.

\section{Los Papels del Sujeto en Relación con los Medios de Comunicación Contenidos en el Tweetdeck: el productor, el difusor y el lector}

\section{Resumen:}

En este artículo se investiga el papel del sujeto en relación con los medios de comunicación el contenido en redes sociales, la realización de un estudio sobre el comercio realizado a través de Twitter Tweetdeck. Se propone que el individuo es un centro de intercambio de medios de comunicación, porque la dinámica de referencias comerciales en la web es interpretado por el punto de vista de los suyos. Afinidades que hacen que su perfil y sus interacciones dan su identidad, es también contenido relevante a los contactos que se forman los grupos de interés. Se acerca a los conceptos de cultura, medios de comunicación y representación y se lleva a cabo la investigación cuantitativa en sus hábitos de absorción y procesamiento de información en Tweetdeck. Llegamos a la conclusión de que el sujeto puede tener tres funciones en relación con el contenido de los medios de comunicación, el productor, que comparte y el lector.

\section{Palabras clave:}

Papels do Sujeto. Representación. Contenidos Midiáticos. 


\section{Expediente}

A revista E-Compós é a publicação científica em formato eletrônico da Associação Nacional dos Programas de Pós-Graduação em Comunicação (Compós). Lançada em 2004, tem como principal finalidade difundir a produção acadêmica de pesquisadores da área de Comunicação, inseridos em instituições do Brasil e do exterior.
E-COMPÓS I www.e-compos.org.br I E-ISSN 1808-2599

Revista da Associação Nacional dos Programas de Pós-Graduação em Comunicação.

Brasília, v.14, n.2, maio/ago. 2011.

A identificação das edições, a partir de 2008 passa a ser volume anual com três números.

\section{CONSELHO EDITORIAL}

Afonso Albuquerque, Universidade Federal Fluminense, Brasil Alberto Carlos Augusto Klein, Universidade Estadual de Londrina, Brasil Alex Fernando Teixeira Primo, Universidade Federal do Rio Grande do Sul, Brasil Ana Carolina Damboriarena Escosteguy, Pontifícia Universidade Católica do Rio Grande do Sul, Brasil

Ana Gruszynski, Universidade Federal do Rio Grande do Sul, Brasil Ana Silvia Lopes Davi Médola, Universidade Estadual Paulista, Brasi André Luiz Martins Lemos, Universidade Federal da Bahia, Brasil Ângela Freire Prysthon, Universidade Federal de Pernambuco, Brasil Angela Cristina Salgueiro Marques, Faculdade Cásper Líbero (São Paulo), Brasil Antônio Fausto Neto, Universidade do Vale do Rio dos Sinos, Brasil Antonio Carlos Hohlfeldt, Pontifícia Universidade Católica do Rio Grande do Sul, Brasil Antonio Roberto Chiachiri Filho, Faculdade Cásper Libero, Brasil Arlindo Ribeiro Machado, Universidade de São Paulo, Brasil Arthur Autran Franco de Sá Neto, Universidade Federal de São Carlos, Brasil Benjamim Picado, Universidade Federal Fluminense, Brasil César Geraldo Guimarães, Universidade Federal de Minas Gerais, Brasil Cristiane Freitas Guttreind, Pontifícia Universidade Católica do Rio Grande do Sul, Brasi Denilson Lopes, Universidade Federal do Rio de Janeiro, Brasil Denize Correa Araujo, Universidade Tuiuti do Paraná, Brasil Edilson Cazeloto, Universidade Paulista , Brasil Eduardo Peñuela Cañizal, Universidade Paulista, Brasi Eduardo Vicente, Universidade de São Paulo, Brasi Eneus Trindade, Universidade de São Paulo, Brasil Erick Felinto de Oliveira, Universidade do Estado do Rio de Janeiro, Brasil Florence Dravet, Universidade Católica de Brasília, Brasil Francisco Eduardo Menezes Martins, Universidade Tuiuti do Paraná, Brasi Gelson Santana, Universidade Anhembi/Morumbi, Brasil Gilson Vieira Monteiro, Universidade Federal do Amazonas, Brasi Gislene da Silva, Universidade Federal de Santa Catarina, Brasil Guillermo Orozco Gómez, Universidad de Guadalajara Gustavo Daudt Fischer, Universidade do Vale do Rio dos Sinos, Brasil Hector Ospina, Universidad de Manizales, Colômbia Herom Vargas, Universidade Municipal de São Caetano do Sul, Brasil leda Tucherman, Universidade Federal do Rio de Janeiro, Brasil Inês Vitorino, Universidade Federal do Ceará, Brasi Janice Caiafa, Universidade Federal do Rio de Janeiro, Brasil Jay David Bolter, Georgia Institute of Technology Jeder Silveira Janotti Junior, Universidade Federal de Pernambuco, Brasil João Freire Filho, Universidade Federal do Rio de Janeiro, Brasi
John DH Downing, University of Texas at Austin, Estados Unidos José Afonso da Silva Junior, Universidade Federal de Pernambuco, Brasil José Carlos Rodrigues, Pontifícia Universidade Católica do Rio de Janeiro, Brasil José Luiz Aidar Prado, Pontifícia Universidade Católica de São Paulo, Brasil José Luiz Warren Jardim Gomes Braga, Universidade do Vale do Rio dos Sinos, Brasil Juremir Machado da Silva, Pontifícia Universidade Católica do Rio Grande do Sul, Brasil Laan Mendes Barros, Universidade Metodista de São Paulo, Brasil Lance Strate, Fordham University, USA, Estados Unidos Lorraine Leu, University of Bristol, Grã-Bretanha Lucia Leão, Pontifícia Universidade Católica de São Paulo, Brasil Luciana Panke, Universidade Federal do Paraná, Brasil Luiz Claudio Martino, Universidade de Brasilia, Brasil Malena Segura Contrera, Universidade Paulista, Brasil Márcio de Vasconcellos Serelle, Pontifícia Universidade Católica de Minas Gerais, Brasil Maria Aparecida Baccega, Universidade de São Paulo e Escola Superior de Propaganda e Marketing, Brasil

Maria das Graças Pinto Coelho, Universidade Federal do Rio Grande do Norte, Brasil Maria Immacolata Vassallo de Lopes, Universidade de São Paulo, Brasil Maria Luiza Martins de Mendonça, Universidade Federal de Goiás, Brasil Mauro de Souza Ventura, Universidade Estadual Paulista, Brasil Mauro Pereira Porto, Tulane University, Estados Unidos Nilda Aparecida Jacks, Universidade Federal do Rio Grande do Sul, Brasi Paulo Roberto Gibaldi Vaz, Universidade Federal do Rio de Janeiro, Brasi Potiguara Mendes Silveira Jr, Universidade Federal de Juiz de Fora, Brasil Renato Cordeiro Gomes, Pontifícia Universidade Católica do Rio de Janeiro, Brasil Robert K Logan, University of Toronto, Canadá

Ronaldo George Helal, Universidade do Estado do Rio de Janeiro, Brasil Rosana de Lima Soares, Universidade de São Paulo, Brasil Rose Melo Rocha, Escola Superior de Propaganda e Marketing, Brasil Rossana Reguillo, Instituto de Estudos Superiores do Ocidente, Mexico Rousiley Celi Moreira Maia, Universidade Federal de Minas Gerais, Brasil Sebastião Carlos de Morais Squirra, Universidade Metodista de São Paulo, Brasi Sebastião Guilherme Albano da Costa, Universidade Federal do Rio Grande do Norte, Brasil

Simone Maria Andrade Pereira de Sá, Universidade Federal Fluminense, Brasil Tiago Quiroga Fausto Neto, Universidade de Brasília, Brasi Suzete Venturelli, Universidade de Brasília, Brasil Valério Cruz Brittos, Universidade do Vale do Rio dos Sinos, Brasil Valerio Fuenzalida Fernández, Puc-Chile, Chile Veneza Mayora Ronsini, Universidade Federal de Santa Maria, Brasil Vera Regina Veiga França, Universidade Federal de Minas Gerais, Brasil

\section{COMISSÃO EDITORIAL}

Adriana Braga I Pontifícia Universidade Católica do Rio de Janeiro, Brasil Felipe Costa Trotta I Universidade Federal de Pernambuco, Brasil

CONSULTORES AD HOC

Bárbara Heller, Universidade Paulista, Brasil

Luciana Mielniczuk, Universidade Federal do Rio Grande do Sul, Brasil Micael Herschmann, Universidade Federal do Rio de Janeiro, Brasil EDIČ̃̃ DE TEXTO E RESUMOS I Susane Barros SECRETÁRIA EXECUTIVA I Juliana Depiné EDITORAÇ̃o ELETRÔNICA I Roka Estúdio TRADUÇÃO I Sabrina Gledhill, Sieni Campos, Robert Finnegan
COMPós I www.compos.org.br

Associação Nacional dos Programas de Pós-Graduação em Comunicação

Presidente

Julio Pinto

Pontifícia Universidade Católica de Minas Gerais, Brasi

juliopinto@pucminas.br

Vice-presidente

Itania Maria Mota Gomes

Universidade Federal da Bahia, Brasi

itania@ufba.br

Secretária-Gera

Inês Vitorino

Universidade Federal do Ceará, Brasil

inesvict@gmail.com 